\title{
EFFECT OF NERVE CONDUCTION STUDIES IN HYPOTHYROIDISM - AN OBSERVATIONAL STUDY
}

\author{
LALITHAMMA $\mathrm{A}^{1 *}$, VADIVEL $\mathrm{S}^{2}$, JOHNSON $\mathrm{W}^{3}$, JACOB V, CHITRA T
}

${ }^{1}$ PHD Scholar, Department of Physiology, Bharath University, Chennai, Tamil Nadu, India. ${ }^{2}$ Department of Physiology, Karpaga Vinayaga Institute of Medical Sciences, Chennai, Tamil Nadu, India. ${ }^{3}$ Department of Anatomy, Sree Balaji Medical College and Research Centre, Chennai, Tamil Nadu, India. ${ }^{4}$ Department of Pharmacology, Karpaga Vinayaga Institute of Medical Sciences, Chennai, Tamil Nadu, India. ${ }^{5}$ Department of Pathology, Karpaga Vinayaga Institute of Medical Sciences, Chennai, Tamil Nadu, India. Email: lalitha.dodla@gmail.com

Received: 06 March 2018, Revised and Accepted: 04 May 2018

\section{ABSTRACT}

Objective: This observational study was conducted during the year 2016-2017 to assess the electrodiagnostic evidence of peripheral nerve dysfunction among newly diagnosed hypothyroid patients attending a tertiary care hospital and to find the effect of hormonal treatment after short duration.

Methods: An observational study was conducted in 25 newly diagnosed hypothyroid patients with the age group of 20-60 were included. After obtaining informed consent, all participants were examined with electrodiagnostic workup performed at the initial time of diagnosis and after short duration for median and ulnar nerves of upper limb by (NeuroStim -NS2, EMG/EP/NCV, and MEDICAID SYSTEMS). Electrophysiological parameters such as distal motor latency, amplitude, and conduction velocity were evaluated.

Results: The mean age of study population was $42.7 \pm 12.1$ (23-61) years. The mean values of nerve conduction velocity of motor and sensory median before the treatment were $42.8 \pm 15.7$ and $40.13 \pm 4.19$ and motor and sensory ulnar before treatment were $41.18 \pm 22.4$ and $39.46 \pm 11.9$. The mean values of nerve conduction velocity of motor and sensory median after treatment were $53.35 \pm 4.7$ and $57.3 \pm 5.6$ and motor and sensory ulnar After treatment were $54.56 \pm 2.99$ and $54.09 \pm 12.17$. The result of the study. Shows that there were reduction of conduction velocity before treatment and statistically significant after 3 months duration of treatment with appropriate doses.

Conclusion: After treatment, total triiodothyronine, total thyroxin, free triiodothyronine, free thyroxin, thyroid-stimulating hormone, and median and ulnar nerve motor and sensory functions were normal with appropriate treatment. The involvement of sensory fibers is more than that of the motor fibers.

Keywords: Hypothyroidism, Motor nerve conduction, Sensory nerve conduction, Median nerve, ulnar nerve, Thyroid-stimulating hormone.

(c) 2018 The Authors. Published by Innovare Academic Sciences Pvt Ltd. This is an open access article under the CC BY license (http://creativecommons. org/licenses/by/4. 0/) DOI: http://dx.doi.org/10.22159/ajpcr.2018.v11i8.25696

\section{INTRODUCTION}

There is a wide geographical variation of the prevalence of hypothyroidism ranging between 0.3 and $0.5 \%$ in western countries, more so in developing countries like India [1]. The thyroid gland secretes triiodothyronine $\left(\mathrm{T}_{3}\right)$ and thyroxin $\left(\mathrm{T}_{4}\right)$ hormones [2]. These hormones maintain the level of metabolism in the tissues that is optimal for their normal function [3]. They play an important role in normal tissue growth and maturation and also have a number of effects on the neuromuscular system and brain. As a result, thyroid dysfunction causes various neurological signs and symptoms [4]. In hypothyroidism, thyroid hormone is not produced in enough amounts; it leads to neuropathies due to long-term and untreated hypothyroidism. Some of the usual signs of hypothyroidism are muscle weakness, fatigue, muscular and mental sluggishness, weight gain, constipation, and intolerance to cold [1]. The prevalence of neuromuscular dysfunctions in thyroid disorders was found to be $20 \%-80 \%$ [5-7].

In hypothyroidism, central and peripheral nerve is involved [8]. Patients develop the usual manifestations of peripheral neuropathy as loss of reflexes, proximal muscle weakness, numbness, paraesthesia, and decreased sensations, for example, vibration; joint position and touch pressure, muscle contraction, and relaxation are reduced with prolonged duration [2]. The peripheral neuropathy was detected by electrophysiological testing or by quantitative assessment of vibratory and thermal sensitivity [9]
In many studies conducted in the past, polyneuropathy was observed to be associated with hypothyroidism. The peripheral polyneuropathy may be due to the defect in nerve cell body, axons, or myelin sheath, and it results in decreased nerve conduction velocities and amplitudes in peripheral nerves. Sural and median nerves are affected earlier, and distal and sensory nerves are affected earlier. Carpal tunnel syndrome is the main cause of peripheral nerve damage in hypothyroidism due to median nerve entrapment [10]

The prevalence of neuromuscular abnormalities was found in 58 newly diagnosed patients with hypothyroidism [4] Khedr et al. examined 23 patients with hypothyroidism and found 52\% had peripheral nervous system involvement with entrapment neuropathy in 35\% of patients [11]. In a case-control cross-sectional study, 40 patients with untreated primary hypothyroidism were electrophysiologically examined and neurological abnormalities were observed [12]. The decreased conduction velocities and amplitudes were found by Lai et al. in 14 patients on peripheral nerve conduction studies [13]. Only a few studies have evaluated the functional alterations in central and peripheral nervous systems in subjects with subclinical hypothyroidism. Mostly, the hormonal treatment might reverse the biochemical abnormalities and restores the normal function.

In hypothyroid patients, theentrapment neuropathy and polyneuropathy can be reversed with the appropriate and timely hormonal treatment, especially in the case of entrapment neuropathy [14]. After treatment, 
peripheral conduction velocities found to be return to normal with the abnormality in amplitude still persisted as studied by Lai et al. [13].

At present, a good number of patients is suffering from hypothyroidism which varies in severity as well as duration of disease. Most of the patients are not aware about the consequences as well as the neurological complications of delayed diagnosis and treatment. The hormonal and metabolic changes leading to the electrophysiological changes occur early in the disease.

Various nerve conduction studies have been done previously in patients of hypothyroidism. The investigators studied nerve conduction parameters in hypothyroid patients to observe the functional status of peripheral nerves in thyroid deficiency. The study was undertaken to observe the effect of hypothyroidism on nerve conduction parameters and to find the effect of treatment on the same with short duration in the population of Kanchipuram district.

\section{METHODS}

An observational study was carried out in Karpaga Vinayaga Institute of Medical Sciences and Research Center, Chennai. The patients attending to the medicine outpatient department between 2015 and 2016 were asked to participate in our study. We selected 34 newly diagnosed male and female hypothyroid patients with the age group of 20-60 years from approximately 1000 patients who are come for general checkup. In 34 patients, 3 patients are not come for further checkup and 6 patients are not interested for the study, finally, 25 patients - 20 female and 5 male were selected for this study, and none of these patients received any medical treatment for hypothyroidism. The institutional ethical committee approval was taken. Before enrolment, informed and written consent was taken from all the patients and explained the procedure in local language. All the subjects were enquired about their demographic and socioeconomic variables as well as their personal history of habits of alcohol intake, smoking, any drug history, and general signs

Table 1: Comparison of thyroid profile before and after treatment in hypothyroidism $(n=50)$

\begin{tabular}{|c|c|c|c|c|}
\hline S. No & Variable & $\begin{array}{l}\text { Before } \\
\text { treatment }(n=25)\end{array}$ & $\begin{array}{l}\text { After } \\
\text { treatment }(n=25)\end{array}$ & p \\
\hline 1 & $\mathrm{TT}_{3}$ & $2.02 \pm 2.9$ & $1.30+0.50$ & 0.185 \\
\hline 2 & $\mathrm{TT}_{4}^{3}$ & $4.27 \pm 2.86$ & $5.16 \pm 2.4$ & 0.24 \\
\hline 3 & $\mathrm{TSH}^{4}$ & $32.7 \pm 11.96$ & $5.4 \pm 2.15$ & $0.000 *$ \\
\hline 4 & $\mathrm{FT}_{3}$ & $1.53+0.83$ & $3.55 \pm 0.96$ & $0.000^{*}$ \\
\hline 5 & $\mathrm{FT}_{4}^{3}$ & $0.65 \pm 0.37$ & $1.34 \pm 0.21$ & $0.000^{*}$ \\
\hline
\end{tabular}

$\mathrm{S}^{*}$ Significant, $\mathrm{TT}_{3}$ : Total triiodothyronine, $\mathrm{TT}_{4}$ : Total thyroxin,

TSH: Thyroid-stimulating hormone, $\mathrm{FT}_{3}$ : Free triiodothyronine, $\mathrm{FT}_{4}$ : Free thyroxin and symptoms related to hypothyroidism. Patients with diabetes mellitus, alcoholism, liver, and kidney disease, use of drugs known to cause neuropathy, and patients with hypothyroidism secondary to pituitary disease were excluded from this study. Serum analysis was performed to confirm the hypothyroid state. For this, serum T3, T4, free triiodothyronine $\left(\mathrm{FT}_{3}\right)$, free thyroxin $\left(\mathrm{FT}_{4}\right)$, and thyroid-stimulating hormone (TSH) were determined by enzyme-linked fluorescent assay by MINIVIDAS. Reference values for laboratory are T3 $-0.58-1.49 \mathrm{ng} / \mathrm{ml}$, $\mathrm{T} 4-4.61-9.3 \mu \mathrm{g} / \mathrm{dl}, \mathrm{TSH}-0.25-5 \mu \mathrm{IU} / \mathrm{ml} \mathrm{FT}_{3}-1.95-5.40 \mathrm{pg} / \mathrm{ml}$, and $\mathrm{FT}_{4}-0.82-1.51 \mathrm{ng} / \mathrm{dl}$. Thereafter, all patients received appropriate doses of thyroxin treatment for hypothyroidism and were monthly followed for thyroid profile throughout 3 months period. At the end of $3^{\text {rd }}$ month, biochemical analysis and electrodiagnostic evaluation were repeated.

\section{Nerve conduction study (NCV)}

In all subjects, NCV was performed by NeuroStim-NS2, EMG/EP/NCV, MEDICAID SYSTEMS available in research laboratory, Department of Physiology, Chennai. Motor and sensory nerve conduction studies were done in all subjects which included the determination of motor and sensory nerve conduction velocity, amplitude and distal motor latencies of median, and ulnar nerves. Ground electrodes were placed between stimulating and recording electrodes. Surface disc electrodes were placed on abductor pollicis brevis for median nerve and abductor digiti minimi for ulnar nerve. Settings for upper limb duration were set up at $100 \mu \mathrm{s}$, sweep speed was $5 \mathrm{~ms} / \mathrm{D}$, and filter was between $2 \mathrm{~Hz}$ and $5 \mathrm{KHz}$. The room temperature was maintained at $37^{\circ} \mathrm{C}$ throughout the test.

\section{Statistical analysis}

The mean values of all parameters in hypothyroidism before and after treatment were statistically analyzed by applying paired t-test and calculated $p$ values using SPSS 22 version. $p$ value was considered statistically significant if found to be $<0.05$.

\section{RESULTS}

The mean age of study population was $42.7 \pm 12.1$ (23-61) years. All were newly diagnosed hypothyroid patients and with electrodiagnostic evidences were recorded and reevaluated by biochemical and electrophysiological studies after a short duration of treatment. The thyroid parameters of study population before and after treatment were shown in Table 1 . Total triiodothyronine $\left(\mathrm{TT}_{3}\right)$ and total thyroxin $\left(\mathrm{TT}_{4}\right.$ ) levels were statistically not significant. $\mathrm{TSH}, \mathrm{FT}_{3}$, and $\mathrm{FT}_{4}$ levels were statistically significant.

Table 2 summarizes the electrodiagnostic evidences among study population. Latency, amplitude, and nerve conduction of median motor and median sensory nerves were statistically significant. Latency and

Table 2: Comparison of motor and sensory nerve conduction parameters in upper limb $(n=50)$

\begin{tabular}{|c|c|c|c|c|}
\hline S. No & Nerve & Before treatment $(n=25)$ & After treatment $(n=25)$ & p \\
\hline \multirow[t]{4}{*}{1} & Median motor & & & \\
\hline & DL (ms) & $4.8 \pm 0.8$ & $4.02 \pm 0.63$ & $0.005^{*}$ \\
\hline & Amplitude (mV) & $3.99 \pm 1.75$ & $5.89 \pm 1.01$ & $0.000 *$ \\
\hline & $\mathrm{NCV}(\mathrm{m} / \mathrm{s})$ & $42.8 \pm 15.7$ & $53.35 \pm 4.7$ & $0.004 *$ \\
\hline \multirow[t]{4}{*}{2} & Ulnar Motor & & & \\
\hline & DL (ms) & $4.6 \pm 1.5$ & $4.2 \pm 0.8$ & 0.287 \\
\hline & Amplitude (mV) & $4.2 \pm 0.8$ & $5.9 \pm 1.91$ & $0.001^{*}$ \\
\hline & $\mathrm{NCV}(\mathrm{m} / \mathrm{s})$ & $41.18 \pm 22.4$ & $54.56 \pm 2.99$ & 0.009 \\
\hline \multirow[t]{4}{*}{3} & Median Sensory & & & \\
\hline & DL (ms) & $2.1 \pm 0.8$ & $2.9 \pm 0.7$ & $0.003^{*}$ \\
\hline & Amplitude (mV) & $7.97 \pm 5.7$ & $15.2 \pm 6.07$ & $0.002 *$ \\
\hline & $\mathrm{NCV}(\mathrm{m} / \mathrm{s})$ & $40.13 \pm 4.19$ & $57.3 \pm 5.6$ & $0.000^{*}$ \\
\hline \multirow[t]{4}{*}{4} & Ulnar Sensory & & & \\
\hline & DL (ms) & $2.61 \pm 0.89$ & $2.4 \pm 0.2$ & 0.491 \\
\hline & Amplitude (mV) & $11.6 \pm 8.6$ & $16.19 \pm 1.4$ & 0.022 \\
\hline & $\mathrm{NCV}(\mathrm{m} / \mathrm{s})$ & $39.46 \pm 11.9$ & $54.09 \pm 12.17$ & $0.002^{*}$ \\
\hline
\end{tabular}

*Significant, DL: Distal latency, NCV: Nerve conduction study 
amplitude of ulnar sensory and latency and conduction velocity of ulnar motor were not significant, and amplitude of ulnar motor and nerve conduction of ulnar sensory was statistically significant.

\section{DISCUSSION}

In this study, all hypothyroid patients had significantly higher TSH levels and lower $\mathrm{FT}_{3}, \mathrm{FT}_{4} \mathrm{TT}_{3}$, and $\mathrm{TT}_{4}$ levels before the appropriate treatment. After short duration of treatment, $\mathrm{TSH}, \mathrm{FT}_{3}$, and $\mathrm{FT}_{4}$ were significantly normal and $\mathrm{TT}_{3}$ and $\mathrm{TT}_{4}$ were statistically not significant. In nerve conduction parameters, latency, amplitude, and nerve conduction of median motor and median sensory nerves were statistically significant. Latency and amplitude of ulnar sensory and latency and conduction velocity of ulnar motor were not significant, and amplitude of ulnar motor and nerve conduction of ulnar sensory was statistically significant. At the initial time of assessment, all patients showed nerve conduction abnormalities. It was returned to normal after appropriate treatment.

This study showed significantly prolonged distal latencies except in ulnar sensory, reduced amplitude, and slowed conduction velocities in median and ulnar nerves. These findings are consistent with that reported by Kececi et al. 2006 [14] and El-Salem K et al. 2006 [15]. However, the sample size for Kececi et al. is more than our study. Conduction velocity and amplitude decreased in Lai et al. [13]. Furthermore, it is well known that conduction velocity which denotes fastness with which nerve signal spreads determined by myelination, diameter and length of the axon [16]. It is well established that thyroid hormones have profound effects on mitochondrial oxidative activity, synthesis and degradation of proteins, sensitivity to catecholamines, differentiation of muscle fibers, and capillary growth and level of antioxidant enzymes and compounds [17]. Demyelination due to oxidative damage to myelin membrane or oligodendroglial cells may result in decrease in nerve conduction velocity [18]. Fall in thyroxin hormone has decreased membrane excitability by decreasing the sodium entry responsible for shoot up of action potential due to hyponatremia[20].

The mechanisms involved in the development of neuropathy in hypothyroidism are not yet fully established. The neurological dysfunction associated with hypothyroidism may be a result of hormonal imbalance or may be related to the immune mechanisms associated with thyroid diseases [21]. Some investigators suggested that the weight gain in the hypothyroid may be a contributory factor for neuropathy. In addition, the deposition of mucopolysaccharides in the tissues surrounding the nerves or the myxedematous tissue may also lead to compression over the peripheral nerves, thereby resulting in swelling and degeneration of the nerves [22,23]. A similar mechanism of nerve damage has been postulated for peripheral neuropathy in carpal tunnel syndrome. The median nerve entrapment at the wrist caused by the deposition of mucinous material in the tissues surrounding the nerve is one of the most frequent causes of peripheral nerve damage in hypothyroidism $[10,20]$. Involvement of sensory may be due to axonal degeneration of sensory nerve. It is identified that sensory nerve is affected earlier than motor. However, it is not clear why sensory nerve is affected earlier than motor nerve. However, it is not clear why sensory nerve is affected earlier than motor nerve.

Limitation of our study was that the duration of the treatment was less and sample size also less. In further studies, we will increase the sample size as well as the duration of the treatment. We did not show the F wave study and electromyographic findings in this article and also body mass index also not shown in this study.

\section{CONCLUSION}

The results of this study after a short duration of treatment demonstrated that the findings related to thyroid profile and nerve conduction parameters can be reversible in a period of short duration with appropriate treatment. The chance of medical treatment must be given to patients before considering surgical treatment. And also, early detection of thyroid disorders and electrophysiological studies are to be conducted in hypothyroid subjects to detect peripheral neuropathy because early detection can reverse the condition by appropriate thyroxin treatment.

\section{ACKNOWLEDGMENT}

Authors of the present study are grateful to the Department of Physiology and Medicine and Managing Director, Karpaga Vinayaga Institute of Medical Sciences and Research Centre for providing all facilities to carry out the work.

\section{AUTHOR'S CONTRIBUTION}

The corresponding author (Lalithamma. A) is the principal investigator of the present work. The second, third, fourth, and fifth authors guided and monitored the experimental design, data compilation, and corrected the manuscript.

\section{CONFLICTS OF INTEREST}

The authors do not have any conflict of interest.

\section{REFERENCES}

1. Hebbari S, Kumar S, Amin S, Doizode S. Subclinical hypothyroidism in pregnancy; is there a need for pharmacological intervention? Int J Pharm Pharm Sci 2017;9:186-91

2. Hall JE, Guyton AC. Textbook of Medical Physiology $12^{\text {th }}$ ed. India: Elsevier Publications; 2013. p. 565-76.

3. Ganong WF. Review of Medical Physiology. $22^{\text {nd }}$ ed. New York: McGraw Hills Publications; 2005. p. 317

4. Ajeena IM. Prevalence of neuromuscular abnormalities in newly diagnosed patients with thyroid dysfunction. Am J Res Commun 2013;1:79-88.

5. Gupta N, Arora M, Sharma R, Arora KS. Peripheral and central nervous system involvement in recently diagnosed cases of hypothyroidism. an electrophysiological study. Ann Med Health Sci Res 2016;6:261-6.

6. Duyff RF, Van den Bosch J, Laman DM, van Loon BJP, Linssen WH. Neuromuscular findings in thyroid dysfunction: A prospective clinical and electro diagnostic study. J Neurol Neurosurg Psychiatry 2000;68:750-5.

7. Parkhad SB, Palve SB, Chandrasekhar MC, Shankari P. Assessment and comparison of electrophysiological findings in thyroid dysfunction patients of Kanchipuram District. Int J Biol Med Res 2015;6:5068-71.

8. Sankareswari A, Shreen LA, Vigil TD, Naveen S, Chandrasekhar M. Evaluation of peripheral nerve conduction and visual evoked potential in newly diagnosed hypothyroid females. Int J Med Res Health Sci 2016;5:43-6.

9. Kumar PR, Kalshetti SM, Bhatt JK. Supplementation of a-lipoic acid in diabetic peripheral neuropathy. A Prospective open label randomized controlled trial. Int J Pharm Pharm Sci 2014;6:90-3.

10. Nemni R, Bottacchi E, Fazio R, Mamoli A, Corbo M, Camerlingo M, et al. Polyneuropathy in hypothyroidism: Clinical, electrophysiological and morphological findings in four cases. J Neurol Neurosurg Psychiatry 1987;50:1454-60.

11. Khedr EM, El-Toony LF, Tarkhan MN, Abdella G. Peripheral and central nervous system alterations in hypothyroidism: Electrophysiological findings. Neuropsychobiology 2000;41:88-94.

12. Eslamian F, Bahrami A, Aghamohammadzadeh N, Niafar $M$, Salekzamani Y, Behkamrad K. Electrophysiological changes in patients with untreated primary hypothyroidism. J Clin Neurophysiol 2011;28:323-8

13. Lai CL, Liu CK, Tai CT, Lin RT, Howng SL. A study of central and peripheral nerve conduction in patients with primary hypothyroidism: The effects of thyroxin replacement. Kaohsiung J Med Sci 1998; 14:294-302.

14. Kececi H, Degirmenci Y. Hormone replacement therapy in hypothyroidism and nerve conduction study. Neurophysiol Clin 2006;36:79-83.

15. El-Salem K, Ammani F. Neurophysiological changes in neurologically asymptomatic hypothyroid patients: A prospective cohort study. J ClinNeurophysiol 2006;23:568-72.

16. Mishra UK, Kalitha J. Text Book of Clinical Neurophysiology. 2nd ed. 
New Delhi: MBD Publishers; 2005.

17. Kedlaya D. Loma. Hypothyroid Myopathy. Linda, CA: Loma Linda University School of Medicine, Updated; 2007.

18. Gabriel Bucurescu, Thyroid Diseases 2006.

19. Abbott RJ, O'Malley BP, Barnett DB. Central and peripheral nerve conduction in thyroid dysfunction: The influence of L-thyroxin therapy compared with warming upon the conduction abnormalities of primary hypothyroidism. Clin Sci (Lond) 1988;64:617-22.

20. Adikesavan B, Gowdhaman N, Rao BV, Balasubramanian K. A study of nerve conduction velocity in newly diagnosed hypothyroid females.
World J Med Sci 2013;9:198-201.

21. Yuksel G, Karlikaya G, Tanridag T, Us O, Akyuz G. Nerve conduction studies, SEP and blink reflex studies in recently diagnosed, untreated thyroid disease patients. J Neurol Sci (Turkish) 2007;24:7-15.

22. Jalilzadeh SH, Bahrami A, Eftekharosadat B, Mobasseri M, Pezeshki Z. Peripheral nerve function in subclinical hypothyroidism: A case-control study. Int J Endocrinol Metab 2006;4:78-83.

23. Yeasmin S, Begum N, Begum S. Motor neuropathy in hypothyroidism: Clinical and electrophysiological findings. BSMMU J 2008;1:15-8. 